\title{
Ghrelin after chemotherapy as a prognostic predictor of progression-free survival in patients with muscle-invasive bladder cancer
}

\author{
Masayuki Tomioka ${ }^{1}$, Tohru Yoneyama ${ }^{2}$, Yuki Tobisawa ${ }^{2}$, Kota Kawase ${ }^{1}$, Chie Nakai ${ }^{1}$, Manabu Takai $^{1}$, \\ Daiki Kato $^{1}$, Koji Iinuma ${ }^{1}$, Keita Nakane ${ }^{1}$, Kosuke Mizutani ${ }^{1}$, Yasuhiro Hashimoto ${ }^{2}$, Takuya Koie ${ }^{1}$ \\ ${ }^{1}$ Department of Urology, Gifu University Graduate School of Medicine, Gifu, Japan; ${ }^{2}$ Department of Urology, Hirosaki University Graduate School \\ of Medicine, Hirosaki, Japan \\ Contributions: (I) Conception and design: T Koie, T Yoneyama, Y Tobisawa; (II) Administrative support: T Koie, T Yoneyama, Y Tobisawa; (III) \\ Provision of study materials or patients: All authors; (IV) Collection and assembly of data: All authors; (V) Data analysis and interpretation: All \\ authors; (VI) Manuscript writing: All authors; (VII) Final approval of manuscript: All authors. \\ Correspondence to: Takuya Koie. Department of Urology, Gifu University Graduate School of Medicine, 1-1 Yanagido, Gifu, Japan. \\ Email: goodwin@gifu-u.ac.jp.
}

Background: Although the patients with muscle-invasive bladder cancer (MIBC) generally have poor prognosis, the utility of these biomarkers for the prediction of oncological outcomes in MIBC has not been completely explored. Ghrelin regulates processes associated with cancer, including cell proliferation, apoptosis, cell migration, cell invasion, and angiogenesis. Thus, we aimed to evaluate the impact of serum ghrelin levels on survival in MIBC.

Methods: In this study, we reviewed the clinical and pathological records of 56 patients who were diagnosed with MIBC between November 2015 and November 2019 at Gifu and Hirosaki University Hospitals. We focused on 27 patients who had received chemotherapy and collected blood samples before and after chemotherapy. Blood samples were collected before chemotherapy and after completing two cycles of chemotherapy. Serum acyl (AG) and desacyl ghrelin (DG) were measured using AG and DG enzymelinked immunosorbent assay kits (SCETI, Tokyo, Japan), respectively.

Results: The 3-year overall and progression-free survival (PFS) rates were $82.9 \%$ and $68.3 \%$, respectively. According to the AG level after chemotherapy, the 3-year PFS rates were $77.5 \%$ and $53.0 \%$ in patients with $\mathrm{AG}$ levels $\geq 1.34$ and $<1.34 \mathrm{pg} / \mathrm{mL}$, respectively $(\mathrm{P}=0.038)$. With regard to $\mathrm{DG}$ levels after chemotherapy, the 3 -year PFS rates were $90.9 \%$ and $43.3 \%$ in patients with DG levels $<92.3$ and $\geq 92.3 \mathrm{pg} / \mathrm{mL}$, respectively $(\mathrm{P}=0.039)$. On multivariate analysis, serum AG levels were significantly associated with PFS.

Conclusions: This study suggested the usefulness of the ghrelin as a prognostic predictor of PFS in patients with MIBC.

Keywords: Muscle-invasive bladder cancer (MIBC); acyl ghrelin (AG); desacyl ghrelin (DG); predictive marker; progression-free survival (PFS)

Submitted Dec 09, 2020. Accepted for publication Jan 27, 2021.

doi: $10.21037 /$ tau-20-1489

View this article at: http://dx.doi.org/10.21037/tau-20-1489

\section{Introduction}

Bladder cancer (BC) is the most common type of malignant tumor occurring in the urinary tract (1). In total, $25-30 \%$ of patients with $\mathrm{BC}$ are diagnosed with muscle-invasive $\mathrm{BC}$
(MIBC) (2). Although radical cystectomy (RC) with extended pelvic lymphadenectomy is the standard treatment for MIBC (3), half of the patients with MIBC develop locoregional recurrence and/or distant metastasis, including the lymph 
nodes, lung, liver, and bone, within 2 years of surgery (4-6). In addition, the 5-year overall (OS) and progression-free survival (PFS) rates in patients with $\mathrm{MIBC}$ are $50-70 \%(5,6)$. However, patients who are pathologically diagnosed with T3/T4 BC or lymph node involvement according to the American Joint Committee on Cancer (AJCC) Staging Manual (7) generally have poor prognosis, and their OS rate is only $10-40 \%(4,5)$.

To date, postoperative tumor recurrence and progression is a serious problem for patients with MIBC. Neoadjuvant chemotherapy, radiotherapy, and immunotherapy may reduce the possibility of MIBC recurrence and progression. However, it is difficult to develop a systemic treatment strategy for individual patients with MIBC because of the different mechanisms of tumor progression and recurrence (8). Therefore, determination of novel and effective prognostic biomarkers is needed to predict and improve the prognosis of patients with MIBC (8). Wang et al. reported that ribosome-binding protein 1 was associated with BC migration, invasion, and prognosis (9). Several studies have demonstrated that hematological biomarkers, including C-reactive protein (CRP), butyrylcholinesterase (BChE), neutrophil-to-lymphocyte ratio, and platelet-to-lymphocyte ratio, can help predict tumor occurrence and progression (10-12). However, the utility of these biomarkers for the prediction of oncological outcomes in MIBC has not been completely explored.

Ghrelin, a novel hormone, increases appetite and growth hormone secretion. It has two different forms-acyl (AG) and desacyl ghrelin (DG) (13). The roles of ghrelin include stimulation of food intake, promotion of carbohydrate utilization, regulation of adiposity, regulation of insulin secretion, and control of blood glucose level (14). Serum ghrelin also regulates processes associated with cancer, including cell proliferation, apoptosis, cell migration, cell invasion, and angiogenesis (15). However, the precise role of ghrelin in the regulation of a number of processes related to cancer progression, especially MIBC, is unclear (16). Thus, we aimed to evaluate the impact of serum ghrelin levels on survival in MIBC patients receiving chemotherapy.

We present the following article in accordance with the TREND reporting checklist (available at http://dx.doi. org/10.21037/tau-20-1489).

\section{Methods}

\section{Patients}

In this study, we reviewed the clinical and pathological records of 56 patients who were diagnosed with MIBC between November 2015 and November 2019 at Gifu and Hirosaki University Hospitals. We focused on 27 patients who had received chemotherapy and collected blood samples before and after chemotherapy. Informed consent was obtained from all participants. Eligibility criteria for participation in this study were as follows: histologically confirmed MIBC without distant metastases; Eastern Cooperative Oncology Group (ECOG) performance status of $0-1$; adequate bone marrow function (absolute neutrophil count $\geq 1,500 / \mathrm{m}^{3}$ and platelet count $\geq 100,000 / \mathrm{m}^{3}$ ), adequate renal function (creatinine $<2.0 \mathrm{mg} / \mathrm{dL}$ and/or creatinine clearance $>40 \mathrm{~mL} / \mathrm{min}$ ), and adequate hepatic function (total bilirubin $<1.5 \mathrm{mg} / \mathrm{dL}$ ). Patients who had previously received radiation therapy to the urinary bladder or pelvis before surgery were excluded.

The study was conducted in accordance with the Declaration of Helsinki (as revised in 2013). The study was approved by the Institutional Review Board of Gifu University (2018-212) and Hirosaki University (2017-1108) and informed consent was taken from all the patients.

\section{Schedule of chemotherapy}

All treatments were performed at our institutions. The chemotherapy regimen consisted of $1,000 \mathrm{mg} / \mathrm{m}^{2}$ of gemcitabine (GEM) administered on days 1,8 , and 15 and $70 \mathrm{mg} / \mathrm{m}^{2}$ of cisplatin (CDDP) or carboplatin (CBDCA), with an area under the curve of 5 according to Calvert's formula, on day 2 (17). Each treatment cycle lasted for 21-28 days. The patients received at least two cycles of chemotherapy. The patients were identified as CDDP ineligible if they met at least one of the following criteria: ECOG performance status of 2, creatinine clearance $<60 \mathrm{~mL} / \mathrm{min}$, hearing loss grade $\geq 2$, neuropathy grade $\geq 2$, and/or New York Heart Association Class III heart failure (18).

\section{Patients evaluation}

The following baseline information was obtained from each patient: complete medical history, physical examination findings, ECOG performance status, abdominal and pelvic computed tomography (CT) or magnetic resonance imaging (MRI) findings, and chest radiography or CT findings.

The diagnosis of MIBC was confirmed by pathologists at our institution by reviewing the results of transurethral resection. Tumor staging was performed according to the 
staging system defined in the AJCC Staging Manual (7).

All patients underwent CT or MRI every 3-6 months until disease progression according to the findings of the radiological evaluation, which was performed after administration of chemotherapy.

\section{Measurement of blood samples}

Blood samples were collected before chemotherapy and after completing two cycles of chemotherapy. Leukocyte count, neutrophil count, lymphocyte count, platelet count, lactate dehydrogenase levels, CRP levels, BChE levels, and serum ghrelin levels were measured prior to chemotherapy and after completing two cycles of chemotherapy. AG and DG levels were measured using AG and DG enzymelinked immunosorbent assay kits (SCETI, Tokyo, Japan), respectively.

\section{Endpoints}

The primary endpoint was PFS. PFS was defined as the time from chemotherapy to the appearance of locoregional and/or distant metastasis on CT.

\section{Statistical analysis}

Data were analyzed using Statistical Package for the Social Sciences software version 24.0 (IBM Corp., Armonk, NY, USA). Categorical and continuous variables were compared using the chi-square test and the Kruskal-Wallis test, respectively. Survival after chemotherapy was analyzed using the Kaplan-Meier method. Survival according to subgroup was analyzed using the log-rank test. The cutoff values for covariates were defined as the minimal value for (1 - sensitivity $)^{2}+(1-\text { specificity })^{2}$ according to the area under the receiver operating characteristic curve (19). All $\mathrm{P}$ values were two sided, and a $\mathrm{P}$ value of $<0.05$ was considered significant.

\section{Results}

\section{Patient characteristics}

The baseline characteristics of the patients are listed in Table 1. Fifteen patients did not provide written informed consent for this study and data for 4 patients were missing. All patients were diagnosed with muscle-invasive urothelial carcinoma based on the results of histological examination of the specimens obtained via transurethral resection. A total of $23(85.2 \%)$ patients underwent RC after chemotherapy, $3(11.1 \%)$ received adjuvant chemotherapy after RC. Of the patients who received adjuvant chemotherapy, two received GEM and CDDP and one was administered GEM plus CBDCA. The median number of adjuvant chemotherapy cycles was two. One 86-year-old patient $(3.7 \%)$ received 4 cycles of GEM and CBCDA as palliative therapy.

The demographic data of patients who were classified into two groups according to the status of locoregional and/ or distant metastasis are listed in Table 2.

\section{Oncological outcomes}

The 3-year OS and PFS rates were $82.9 \%$ and $68.3 \%$, respectively. After the follow-up period, 5 (18.5\%) patients died of BC, $1(0.4 \%)$ patient died of malignant lymphoma, and $1(0.4 \%)$ patient died of acute pan-peritonitis. Conversely, all patients who did not undergo RC were still alive at the end of the follow-up period. The median follow-up period in patients who did not undergo RC was 10.5 months. Eight (29.6\%) patients developed clinical recurrences. The most common site of clinical recurrence was the lymph nodes [ 4 patients $(50 \%)$ ]. The other recurrence sites were locoregional [2 patients $(7.4 \%)]$ and the lungs [2 patients $(7.4 \%)]$.

According to the AG level after chemotherapy, the 3 -year PFS rates were $77.5 \%$ and $53.0 \%$ in patients with AG levels $\geq 1.34$ and $<1.34 \mathrm{pg} / \mathrm{mL}$, respectively $(\mathrm{P}=0.038$; Figure 1). With regard to DG levels after chemotherapy, the 3 -year PFS rates were $90.9 \%$ and $43.3 \%$ in patients with DG levels $<92.3$ and $\geq 92.3 \mathrm{pg} / \mathrm{mL}$, respectively ( $\mathrm{P}=0.039$; Figure 2). According to CRP level, the 3 -year PFS rates were $79.8 \%$ and $35.7 \%$ in patients with CRP levels of $<0.475$ and $\geq 0.475 \mathrm{mg} / \mathrm{dL}$, respectively $(\mathrm{P}<0.001$; Figure 3). In patients treated with GEM and CDDP and GEM and CBDCA, the 3-year PFS rates were $99.3 \%$ and $41.3 \%$, respectively ( $\mathrm{P}=0.020$; Figure 4$)$. On multivariate analysis, serum AG levels were significantly associated with PFS (Table 3).

\section{Discussion}

To our knowledge, the current study is the first to evaluate the relationship between serum ghrelin levels and oncological outcomes in patients with MIBC who received chemotherapy. In our previous study, we identified $\mathrm{BChE}$ as a potential biomarker for the prediction of MIBC 
Table 1 Patient characteristics $(n=27)$

\begin{tabular}{lc}
\hline Covariates & \\
\hline Age (years, median, interquartile range) & $71(64-74)$ \\
Gender (number, \%) & $25(92.6)$ \\
Male & $2(7.4)$ \\
Female & \\
Histological findings (number, \%) & $26(96.3)$ \\
Urothelial carcinoma & $1(3.7)$ \\
Small cell carcinoma & \\
Clinical Tumor stage (number, \%) & $12(44.4)$ \\
T2 & $13(48.2)$ \\
T3 & $2(7.4)$ \\
T4a & \\
Clinical nodal status (number, \%) & $25(92.6)$ \\
Negative & $2(7.4)$ \\
Positive
\end{tabular}

Body mass index $\left(\mathrm{kg} / \mathrm{m}^{2}\right.$, median, interquartile range)

Pre-chemotherapy

$24.1(21.7-27.5)$

Post-chemotherapy

$24.2(20.9-26.9)$

Chemotherapy regimen (number, \%)

Gemcitabine and cisplatin

$15(55.6)$

Gemcitabine and carboplatin

$12(44.4)$

Leucocyte count ( $/ \mu \mathrm{L}$, median, interquartile range)

Pre-chemotherapy

$6,665(5,835-8,520)$

Post-chemotherapy

$5,435(4,700-7,575)$

Neutrophil count $(/ \mu \mathrm{L}$, median, interquartile range)

Pre-chemotherapy

$4,455(3,330-5,963)$

Post-chemotherapy

$3,355(2,390-5,028)$

Lymphocyte count $\left(\times 10^{3} / \mu \mathrm{L}\right.$, median, interquartile range)

Pre-chemotherapy

$1,771(1,401-2,175)$

Post-chemotherapy

$1,600(995-2,173)$

Platelet count ( $/ \mu \mathrm{L}$, median, interquartile range)

Pre-chemotherapy

2,345 (199.5-3,967.5)

Post-chemotherapy

$283.5(190.5-3,967.5)$

lactate dehydrogenase (U/L, median, interquartile range)

Pre-chemotherapy

178 (168-210)

Post-chemotherapy

$205(185-231)$

Table 1 (continued)

Table 1 (continued)

\begin{tabular}{|c|c|}
\hline \multicolumn{2}{|l|}{ Covariates } \\
\hline \multicolumn{2}{|c|}{ C-reactive protein (mg/dL, median, interquartile range) } \\
\hline Pre-chemotherapy & $0.140(0.049-0.475)$ \\
\hline Post-chemotherapy & $0.357(0.075-1.133)$ \\
\hline \multicolumn{2}{|c|}{ Butyrylcholinesterase (U/L, median, interquartile range) } \\
\hline Pre-chemotherapy & $278(214-301)$ \\
\hline Post-chemotherapy & $248(207-321)$ \\
\hline \multicolumn{2}{|c|}{ Serum acyl-ghrelin levels ( $\mathrm{pg} / \mathrm{mL}$, median, interquartile range) } \\
\hline Pre-chemotherapy & $1.48(1.13-2.51)$ \\
\hline Post-chemotherapy & $1.38(0.82-1.97)$ \\
\hline \multicolumn{2}{|c|}{ Serum des-acyl ghrelin levels ( $\mathrm{pg} / \mathrm{mL}$, median, interquartile range) } \\
\hline Pre-chemotherapy & $54.02(8.85-124.97)$ \\
\hline Post-chemotherapy & $100.89(44.95-147.99)$ \\
\hline $\begin{array}{l}\text { Follow-up period (months, interquartile } \\
\text { range) }\end{array}$ & $42.9(10.8-46.6)$ \\
\hline
\end{tabular}

patient prognosis despite normal liver function with or without hepatic involvement (10). BChE may also be physiologically relevant for the hydrolysis of ghrelin (14). Additionally, BChE may be a key regulator of ghrelin in the peripheral circulation with widespread impacts (20). On the contrary, ghrelin affects physiological functions and pathological states, including insulin release, adiposity, energy homeostasis, and the development and progression of several types of cancers (20). Therefore, we investigated the association between serum ghrelin levels and PFS in patients with MIBC.

Ghrelin is a 28 -amino-acid peptide that stimulates the release of pituitary growth hormone. It was discovered as an intrinsic ligand for the growth hormone-secretagogue receptor in $1999(13,20)$. Ghrelin is mainly produced in the stomach. It has two forms-AG, which is catalyzed by ghrelin $\mathrm{O}$-acyltransferase, whereas DG has no such modification (21). In general, the blood concentration of DG is approximately 4-5 times higher than that of AG (22). AG is recognized as an orexigenic peptide and has several characteristic functions, including secretion of growth hormone, promotion of food intake, gastrointestinal motility, secretion of gastric acid, weight gain, and strong anti-inflammatory action (13,23-25). Conversely, DG is an anorexigenic peptide, and its mechanism of action 
Table 2 Clinical characteristics before and after chemotherapy $(\mathrm{n}=27)$

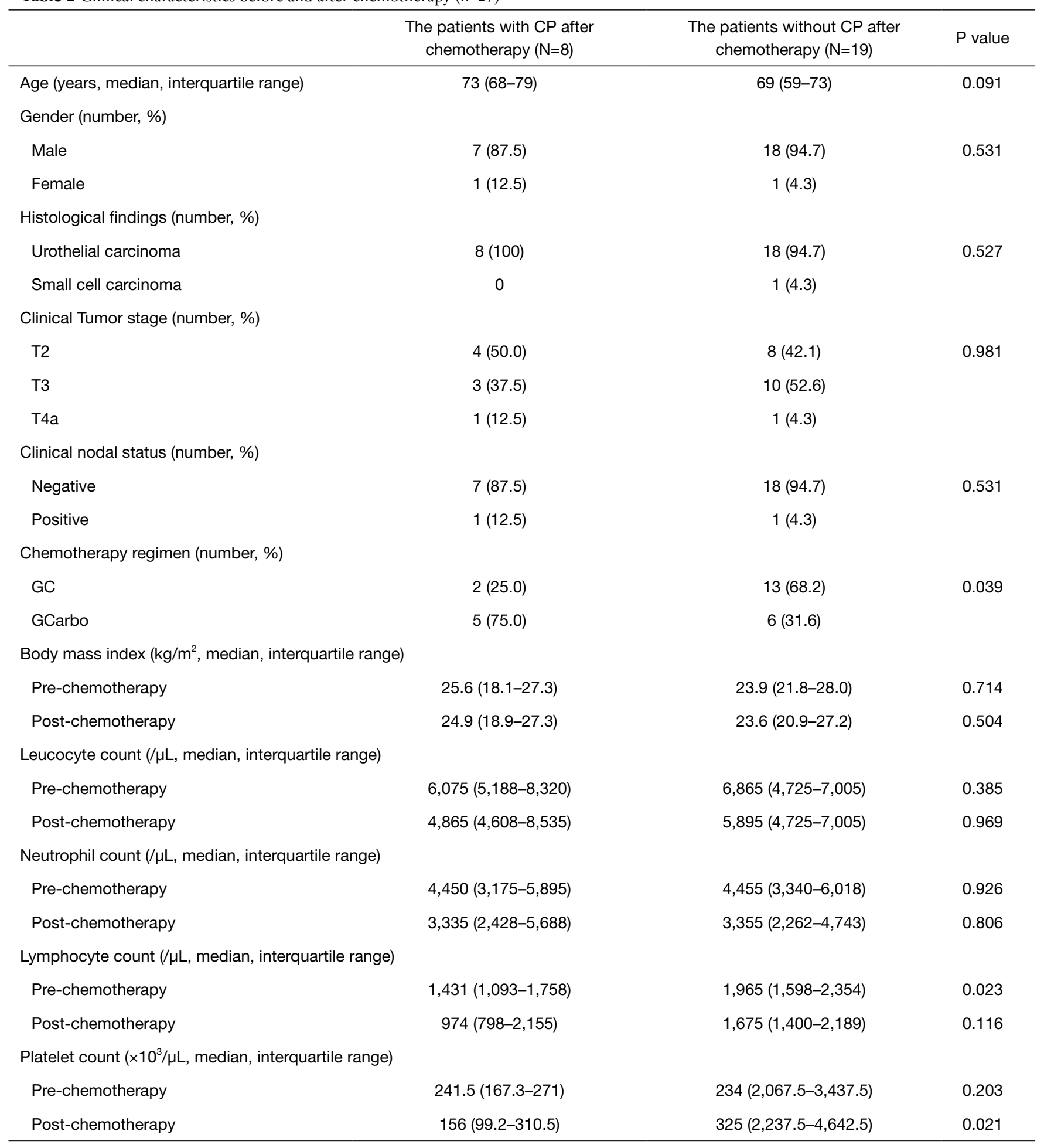

Table 2 (continued) 
Table 2 (continued)

\begin{tabular}{|c|c|c|c|}
\hline & $\begin{array}{c}\text { The patients with } \mathrm{CP} \text { after } \\
\text { chemotherapy }(\mathrm{N}=8)\end{array}$ & $\begin{array}{c}\text { The patients without CP after } \\
\text { chemotherapy }(\mathrm{N}=19)\end{array}$ & $P$ value \\
\hline \multicolumn{4}{|c|}{ Neutrophil-to-lymphocyte ratio (\%, interquartile range) } \\
\hline Pre-chemotherapy & $2.9(2.10-5.58)$ & $2.10(1.67-3.06)$ & 0.236 \\
\hline Post-chemotherapy & $2.9(1.54-5.88)$ & $1.97(1.37-2.90)$ & 0.806 \\
\hline Pre-chemotherapy & $150.2(122.8-202.3)$ & $140.5(86.9-186.0)$ & 0.617 \\
\hline Post-chemotherapy & $134.4(103.2-289.3)$ & $151.8(122-311.7)$ & 0.924 \\
\hline \multicolumn{4}{|c|}{ lactate dehydrogenase $(\mathrm{U} / \mathrm{L}$, median, interquartile range) } \\
\hline Pre-chemotherapy & $174(133-228)$ & $178(170-193)$ & 0.493 \\
\hline Post-chemotherapy & $0.4(0.05-2.65)$ & $0.36(0.09-0.95)$ & 0.522 \\
\hline \multicolumn{4}{|c|}{ Butyrylcholinesterase (U/L, median, interquartile range) } \\
\hline Pre-chemotherapy & $251(160-297)$ & $283(225-303)$ & 0.203 \\
\hline Post-chemotherapy & $236(196-248)$ & $289(225-327)$ & 0.053 \\
\hline \multicolumn{4}{|c|}{ Acyl ghrelin (pg/mL, median, interquartile range) } \\
\hline Pre-chemotherapy & $1.26(0.26-2.38)$ & $1.59(1.20-2.51)$ & 0.298 \\
\hline Post-chemotherapy & $1.14(0.07-1.98)$ & $1.53(0.90-2.01)$ & 0.496 \\
\hline
\end{tabular}

CP, cancer progression; GC, gemcitabine and cisplatin; GCarbo, gemcitabine and carboplatin.

is different from that of $\mathrm{AG}$, including promotion or suppression of food intake (an anti-arteriosclerotic effect), suppression of inflammatory cell infiltration, protection against muscle atrophy, and neuroprotection $(23,24)$.

Ghrelin expression was recently identified in a wide range of normal tissues, including those in the stomach, duodenum, colon, hypothalamus, pituitary, pancreas, placenta, lung, cardiomyocytes, ovaries, and testes (15). Similarly, ghrelin is expressed in various malignant tumor tissues, including those in digestive tract, lung, thyroid, breast, prostate, testicular, pancreatic, and renal carcinomas (15). Grönberg et al. investigated the expression of ghrelin and obestatin protein in 137 patients with breast cancer (26). Immunoreactivity of ghrelin and obestatin was positively correlated with the patients' estrogen receptor status, but it was negatively associated with tumor size, tumor grade, and Ki-67 index (26). Therefore, ghrelin could be a useful prognostic marker for breast cancer due to the correlation between expression levels of ghrelin and survival rates (26). Colorectal cancer cells produce significantly more ghrelin than normal colonocytes (27). Therefore, the tissue expression levels of ghrelin may be highly correlated with the development of more advanced tumors (27). In genitourinary cancer, ghrelin expression has also been observed in the sites of renal cell carcinoma metastasis, including the bones, lungs, adrenal glands, and intestines (28). In prostate cancer cell lines, ghrelin and DG inhibited the proliferation of DU-145 cells, displayed 


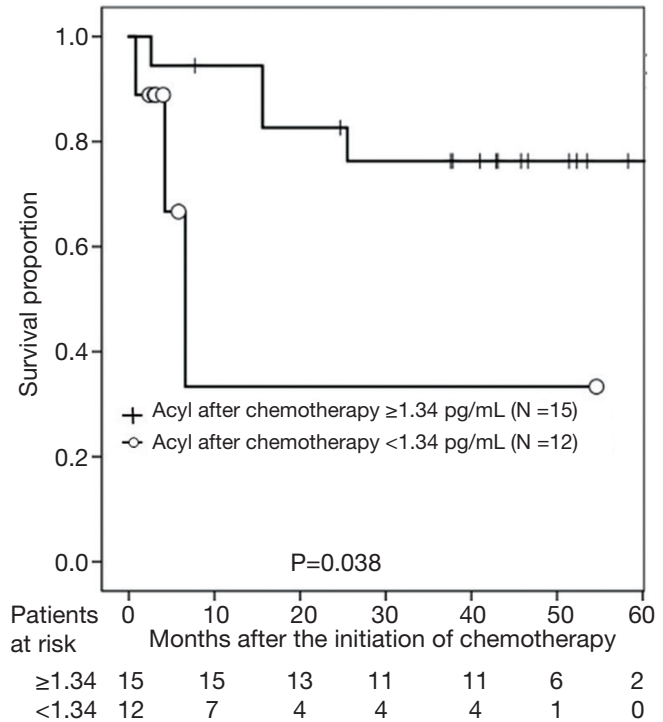

Figure 1 Kaplan-Meier estimates of progression-free survival (PFS) in patients with muscle-invasive bladder cancer after chemotherapy according to acyl ghrelin (AG) levels. The PFS rate was significantly higher in the patients with $\mathrm{AG}$ levels $\geq 1.34 \mathrm{pg} / \mathrm{mL}$ than in those with $\mathrm{AG}$ levels $<1.34 \mathrm{pg} / \mathrm{mL}(\mathrm{P}=0.038)$.

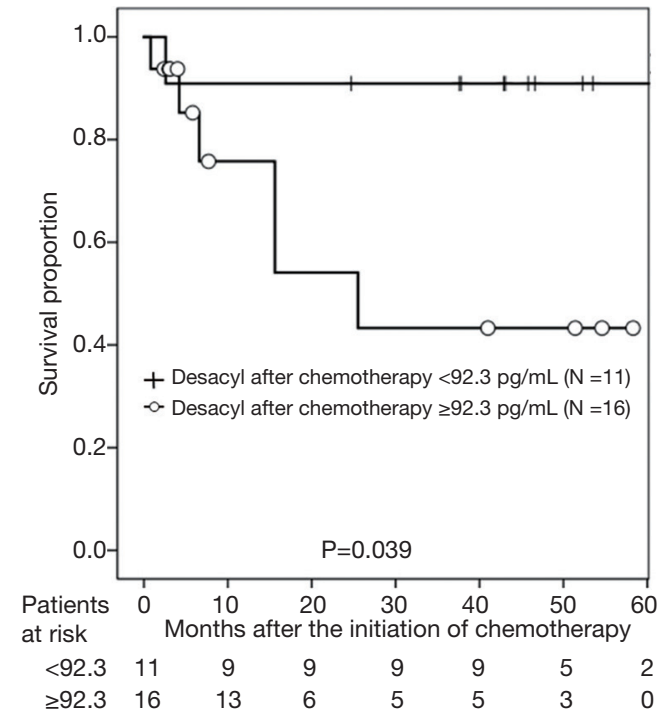

Figure 2 Kaplan-Meier estimates of progression-free survival (PFS) in patients with muscle-invasive bladder cancer after chemotherapy according to desacyl ghrelin (DG) levels. The PFS rate was significantly higher in the patients with DG levels $<92.3 \mathrm{pg} / \mathrm{mL}$ than in those with DG levels $\geq 92.3 \mathrm{pg} / \mathrm{mL}(\mathrm{P}=0.039)$.

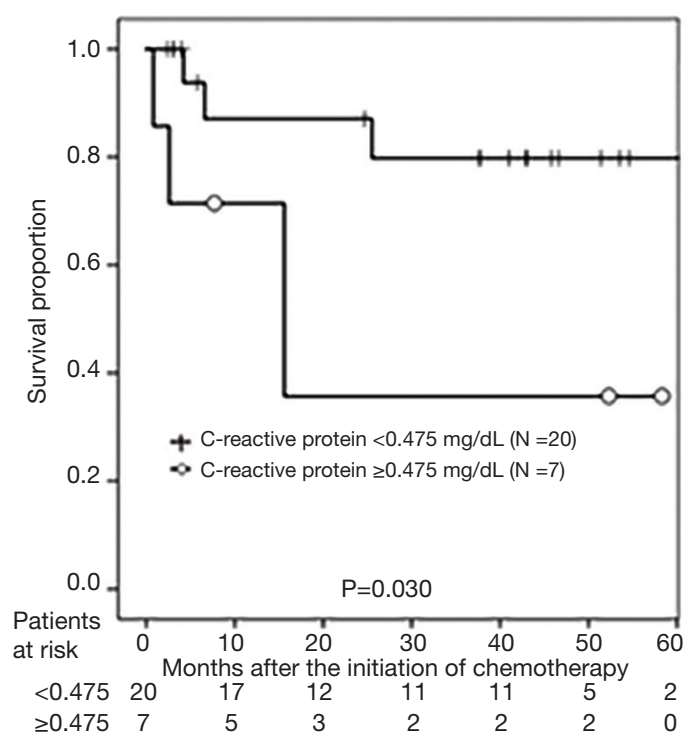

Figure 3 Kaplan-Meier estimates of progression-free survival (PFS) in patients with muscle-invasive bladder cancer before chemotherapy according to C-reactive protein (CRP) levels. The PFS rate was significantly higher in the patients with CRP levels $<0.475 \mathrm{mg} / \mathrm{dL}$ than in those with CRP levels $\geq 0.475 \mathrm{mg} / \mathrm{dL}(\mathrm{P}=0.030$ ).

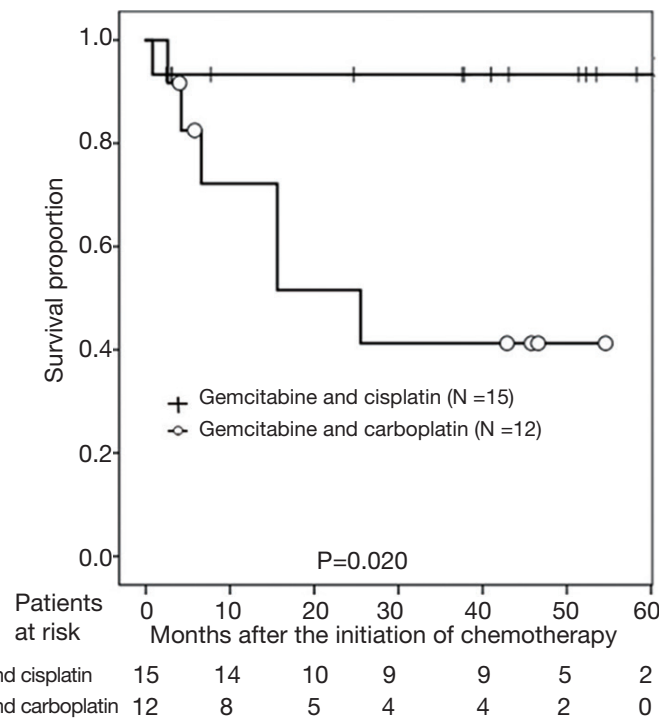

Figure 4 In the patients treated with gemcitabine and cisplatin and gemcitabine and carboplatin, the 3 -year progression-free survival rates were $99.3 \%$ and $41.3 \%$, respectively $(\mathrm{P}=0.020)$. 
Table 3 Multivariate analysis according to progression-free survival (n=27)

\begin{tabular}{lccc}
\hline Covariates & Odds ratio & $95 \% \mathrm{Cl}$ & $\mathrm{P}$ \\
\hline AG after chemotherapy & 0.053 & $0.003-0.820$ & 0.036 \\
DG after chemotherapy & 1.007 & $0.984-1.031$ & 0.536 \\
Chemotherapy regimen & 0.116 & $0.009-1.419$ & 0.092 \\
CRP before chemotherapy & 2.709 & $0.755-9.722$ & 0.126 \\
\hline
\end{tabular}

Cl, confidence interval; AG, acyl ghrelin; DG, desacyl ghrelin; CRP, C-reactive protein.

a biphasic effect in PC-3 cells, and were effective against LNCaP cells (29).

In this study, the CRP levels before chemotherapy, serum ghrelin (AG and DG) levels after chemotherapy, and the GEM plus CDDP regimen were significantly associated with PFS. Most patients with cancer cachexia have higher total plasma ghrelin levels than those without cachexia (29). Although the mechanisms underlying the increase in ghrelin levels in patients with cachexia are unclear, patients with cachexia do not show an increased appetite despite the elevation in ghrelin levels (30). Therefore, the provision of systemic chemotherapy, especially GEM and CDDP, in patients with MIBC may not only improve the oncological outcomes but also the general condition of the patients. In addition, patients with MIBC receiving chemotherapy may have improved antiinflammatory function, resulting in the activation of AG based on multivariate analysis findings. However, a small number of patients were enrolled in this study, therefore, GEM plus CDDP chemotherapy may have affected the improvement with oncological outcomes compared to that in GEM and CDBCA chemotherapy or changes in ghrelin levels.

The present study has few limitations. First, as this study was a retrospective study, there is an inherent potential for bias. Second, this study has a key weakness in that a small number of patients were enrolled and the follow-up period was relatively short.

\section{Conclusions}

This study suggested the usefulness of the ghrelin as a prognostic predictor of PFS in patients with MIBC. Further studies are warranted to determine the usefulness of serum ghrelin as a potential biomarker to predict oncological outcomes, especially OS, in patients with MIBC. Further research is also necessary to determine the role of AG and
DG in MIBC.

\section{Acknowledgments}

Funding: This study was supported by the following grantsin-aid for Scientific Research from the Japan Society for the Promotion of Science: 17K11118.

\section{Footnote}

Reporting Checklist: The authors have completed the TREND reporting checklist. Available at http://dx.doi. org/10.21037/tau-20-1489

Data Sharing Statement: available at http://dx.doi. org/10.21037/tau-20-1489

Conflicts of Interest: All authors have completed the ICMJE uniform disclosure form (available at http://dx.doi. org/10.21037/tau-20-1489). The authors have no conflicts of interest to declare.

Ethical Statement: The authors are accountable for all aspects of the work in ensuring that questions related to the accuracy or integrity of any part of the work are appropriately investigated and resolved. The study was conducted in accordance with the Declaration of Helsinki (as revised in 2013). The study was approved by the Institutional Review Board of Gifu University (2018-212) and Hirosaki University (2017-1108) and informed consent was taken from all the patients.

Open Access Statement: This is an Open Access article distributed in accordance with the Creative Commons Attribution-NonCommercial-NoDerivs 4.0 International License (CC BY-NC-ND 4.0), which permits the noncommercial replication and distribution of the article with 
the strict proviso that no changes or edits are made and the original work is properly cited (including links to both the formal publication through the relevant DOI and the license). See: https://creativecommons.org/licenses/by-nc-nd/4.0/.

\section{References}

1. Siegel R, Naishadham D, Jemal A. Cancer statistics, 2013. CA Cancer J Clin 2013; 63:11-30.

2. Burger M, Catto JW, Dalbagni G, et al. Epidemiology and risk factors of urothelial bladder cancer. Eur Urol 2013;63:234-41.

3. American Joint Committee on Cancer. Urinary Bladder. In: Edge SB, Byrd DR, Compton CC, et al. editors. AJCC Cancer Staging Manual, 7th ed. Springer, New York: 2010; 497-505.

4. Milowsky MI, Rumble RB, Booth CM, et al. American Society of Clinical Oncology Clinical Practice Guideline Endorsement. J Clin Oncol 2016;34:1945-52.

5. Hautmann RE, de Petriconi RC, Pfeiffer C, et al. Radical cystectomy for urothelial carcinoma of the bladder without neoadjuvant or adjuvant therapy: long-term results in 1100 patients. Eur Urol 2012;61:1039-47.

6. Stein JP, Lieskovsky G, Cote R, et al. Radical cystectomy in the treatment of invasive bladder cancer: long-term results in 1,054 patients. J Clin Oncol 2001;19:666-75.

7. Alfred Witjes J, Lebret T, Compérat EM, et al. Updated 2016 EAU guidelines on muscle-invasive and metastatic bladder cancer. Eur Urol 2017;71:462-75.

8. Li P, Cao J, Li J, et al. Identification of prognostic biomarkers associated with stromal cell infiltration in muscle-invasive bladder cancer by bioinformatics analyses. Cancer Med 2020;9:7253-67.

9. Wang M, Liu S, Zhou B, et al. RRBP1 is highly expressed in bladder cancer and is associated with migration and invasion. Oncol Lett 2020;20:203.

10. Koie T, Ohyama C. Yamamoto H, et al. Significance of preoperative butyrylcholinesterase as an independent predictor of survival in patients with muscle-invasive bladder cancer treated with radical cystectomy. Urol Oncol 2014;32:820-5.

11. Zhang L, Li L, Liu J, et al. Meta-analysis of multiple hematological biomarkers as prognostic predictors of survival in bladder cancer. Medicine (Baltimore) 2020;99:e20920.

12. Templeton AJ, McNamara MG, Šeruga B, et al. Prognostic role of neutrophil-to-lymphocyte ratio in solid tumors: a systematic review and meta-analysis. J Natl Cancer Inst 2014;106:dju124.

13. Kawaguchi M, Kanemaru A, Fukushima T, et al. Ghrelin administration suppresses inflammationassociated colorectal carcinogenesis in mice. Cancer Sci 2015;106:1130-6.

14. Schopfer LM, Lockridge O, Brimijoin S. Pure human butyrylcholinesterase hydrolyzes octanoyl ghrelin to desacyl ghrelin. Gen Comp Endocrinol 2015;224:61-8.

15. Chopin LK, Seim I, Walpole CM, et al. The ghrelin axisdoes it have an appetite for cancer progression? Endocr Rev 2012;33:849-91.

16. Lin TC, Hsiao M. Ghrelin and cancer progression. Biochim Biophys Acta Rev Cancer 2017;1868:51-7.

17. Calvert AH, Newell DR, Gumbrell LA, et al. Carboplatin dosage: prospective evaluation of a simple formula based on renal function. J Clin Oncol 1989;7:1748-56.

18. Galsky MD, Hahn NM, Rosenberg J, et al. Treatment of patients with metastatic urothelial cancer "unfit" for cisplatin-based chemotherapy. J Clin Oncol 2011;29:2432-8.

19. Perkins NJ, Schisterman EF. The inconsistency of 'optimal' cutpoints obtained using two criteria based on the receiver operating characteristics curve. Am J Epidemiol 2006;163:670-5.

20. Brimijoin S, Chen VP, Pang Y, et al. Physiological roles for butyrylcholinesterase: a BChE-ghrelin axis. Chem Biol Interact 2016;259:271-5.

21. Kojima M, Hosoda H, Date Y, et al. Ghrelin is a growthhormone-releasing acylated peptide from stomach. Nature 1999;402:656-60.

22. Nikolopoulos D, Theocharis S, Kouraklis G. Ghrelin: a potential therapeutic target for cancer. Regul Pept 2010;163:7-17.

23. Mizutani M, Atsuchi K, Asakawa A, et al. Localization of acyl ghrelin- and des-acyl ghrelin-immunoreactive cells in the rat stomach and their responses to intragastric $\mathrm{pH}$. Am J Physiol Gastrointest Liver Physiol 2009;297:G974-80.

24. Nishida T, Tsubouchi H, Hamada T, et al. Plasma desacyl ghrelin-to-acyl ghrelin ratio is a predictor of postoperative complications and prognosis after pancreaticoduodenectomy. Oncol Lett 2019;18:4974-83.

25. Asakawa A, Inui A, Kaga T, et al. Ghrelin is an appetitestimulatory signal from stomach with structural resemblance to motilin. Gastroenterology 2001;120:337-45.

26. Grönberg M, Fjällskog ML, Jirström K, et al. Expression of ghrelin is correlated to a favorable outcome in invasive breast cancer. Acta Oncol 2012;51:386-93.

27. Waseem T, Javaid-Ur-Rehman, Ahmad F, et al. Role 
of ghrelin axis in colorectal cancer: a novel association. Peptides 2008;29:1369-76.

28. Lin TC, Liu YP, Chan YC, et al. Ghrelin promotes renal cell carcinoma metastasis via Snail activation and is associated with poor prognosis. J Pathol 2015;237:50-61.

29. Cassoni P, Ghé C, Marrocco T, et al. Expression of ghrelin and biological activity of specific receptors for ghrelin and des-acyl ghrelin in human prostate neoplasms and related cell lines. Eur J Endocrinol 2004;150:173-84.

30. Khatib MN, Gaidhane A, Gaidhane S, et al. Ghrelin as a Promising Therapeutic Option for Cancer Cachexia. Cell Physiol Biochem 2018;48:2172-8

Cite this article as: Tomioka M, Yoneyama T, Tobisawa Y, Kawase K, Nakai C, Takai M, Kato D, Iinuma K, Nakane K, Mizutani K, Hashimoto Y, Koie T. Ghrelin after chemotherapy as a prognostic predictor of progression-free survival in patients with muscle-invasive bladder cancer. Transl Androl Urol 2021;10(3):1192-1201. doi: 10.21037/tau-20-1489 